\title{
The Influence of Protective Equipment ON HUMAN MOVEMENTS AND OVERLOADING
}

\author{
Vujica HerZog, N. \& BuChMEISTER, B.
}

Abstract: Paper presents the results of testing firefighter protective equipment. During interventions, firefighters are exposed to strain and stress and above all they are exposed to high temperatures and working in extreme thermal conditions. Since clothes protect firefighter and actually presents the barrier for heat exchange, it is very important to know their characteristics (e.g. thermal insulation) when creating and designing suitable clothes that will offer also normal movement and comfort during work. For testing different protective clothes, thermal manikins are usually used. Thermal manikins represent the anatomical shape of human body and in this way represent a measuring tool. During our research, data on nineteen segments of thermal manikin was observed and thermal insulation was calculated. Thermal insulation usually plays an important role when researching or developing optimal protective clothes used in hot environmental conditions. For studying suitability of firefighters movements' two ergonomics methods were used: OWAS and RULA.

Key words: ergonomics, firefighter, extreme environment, thermal manikin
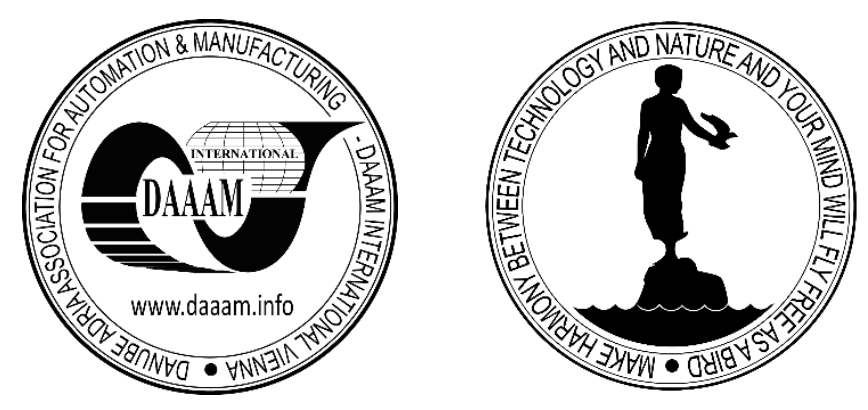

Authors' data: Asist. Prof. Dr. Sc. Vujica Herzog, N[atasa], Full. Prof. Dr. Sc. Buchmeister, B[orut]; University of Maribor, Faculty of Mechanical Engineering, Production Engineering Institute, Smetanova 17, 2000 Maribor, Slovenia, natasa.vujica@um.si, borut.buchmeister@um.si

This Publication has to be referred as: Herzog, N[atasa] V[ujica] \& Buchmeister, B [orut] (2016). The Influence of Protective Equipment on Human Movements and Overloading, Chapter 24 in DAAAM International Scientific Book 2016, pp.267-276, B. Katalinic (Ed.), Published by DAAAM International, ISBN 978-3-902734-09-9, ISSN 1726-9687, Vienna, Austria

DOI: $10.2507 /$ daaam.scibook.2016.24 
Herzog, N. V. \& Buchmeister, B.: The Influence of Protective Equipment on Huma...

\section{Introduction}

Working in hot environment usually presents a high risk for human, especially because of several negative influences from the environment. During interventions, firefighters are exposed to strain and stress and above all they are exposed to high temperatures and working in extreme thermal conditions. To protect the human being it is necessary that the personal protective equipment is carefully planned and designed. Our research was focused on clothes therefore we investigated only characteristics of firefighter suits and trousers (Fig. 1) without additional equipment that includes also gloves, boots, helmet, mask etc.
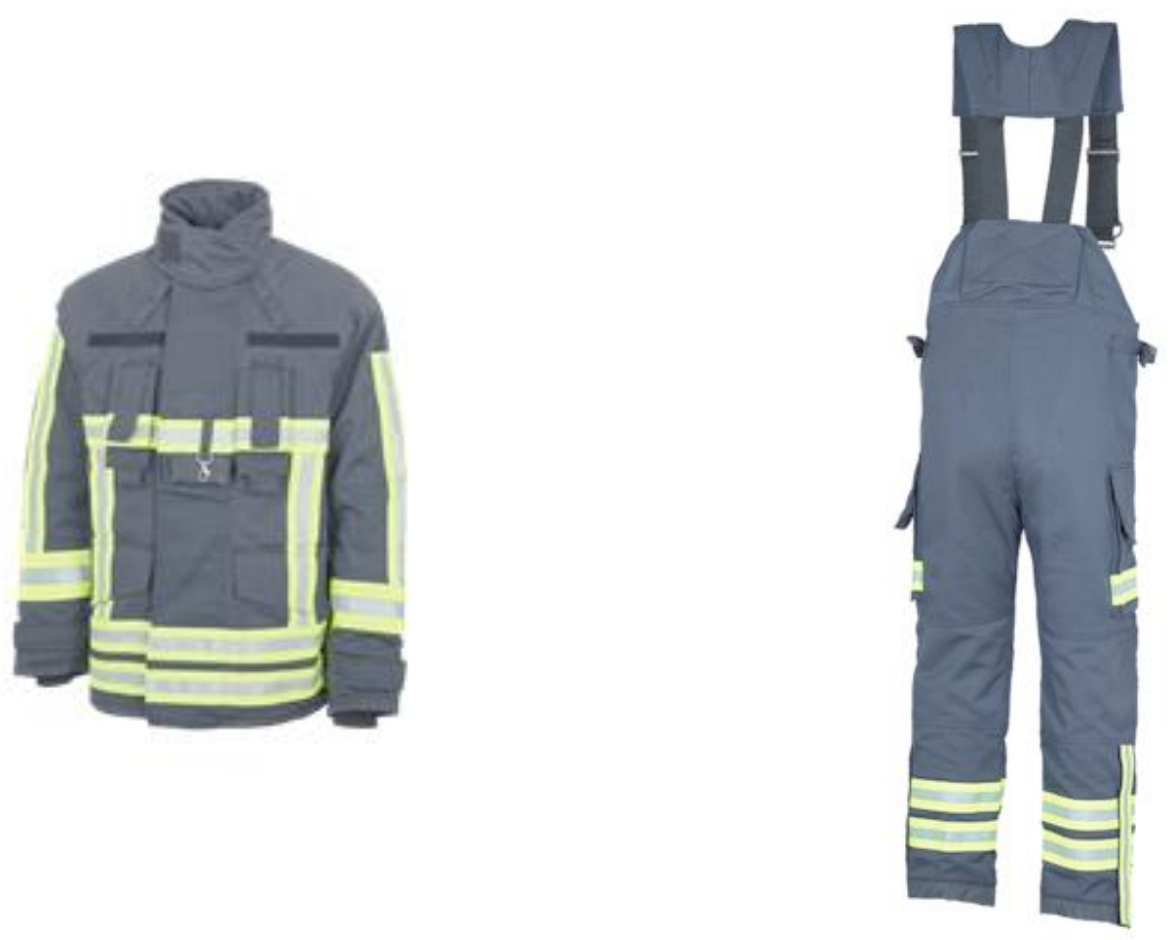

Fig. 1. Firefighter suit and trousers

\section{Research problem}

For testing clothes characteristics thermal manikin was used. Thermal manikins, as anatomical shapes of the human body, were first used in the early 1940's (Holmer, 2004, Andrejiova et al., 2012). Since that, thermal manikins developed much and several possibilities have been introduced such as better heat regulation, better signal quality and control, etc. Thermal manikins of today represent the anatomical shape of the human body and in this way represent a measuring tool, which enables (Pahole et al., 2015; Pavlinic, D. Z.et al., 2011; Zavec Pavlinič, D. et al., 2014):

- relevant simulation of human body heat exchange; whole body and regional,

- measurement of the 3-dimensional heat exchange,

- integration of dry heat losses in a realistic manner,

- method for measuring segmental heat flux whilst testing different personal protective equipment, 
- provision of values for prediction models such as clothing thermal insulation, evaporative resistance and heat loss,

- quick, accurate and repeatable measurements where human testing would be too risky for their lives

Thermal manikin used in our research was designed and made at the Faculty of Mechanical engineering in Laboratory for Intelligent manufacturing and within research group 'Manufacturing technology and automation'. Figure 2 presents naked and dressed manikin.

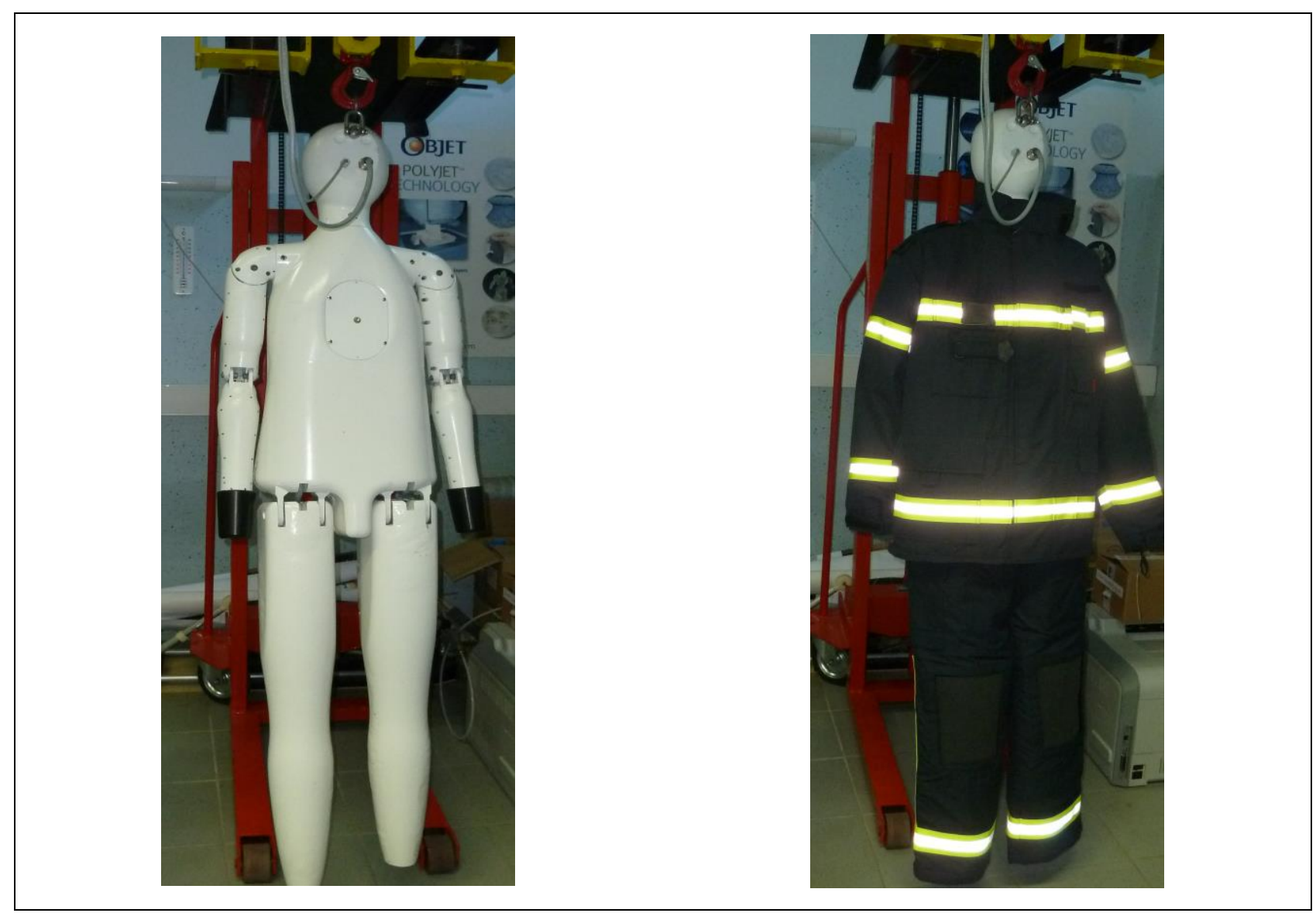

Fig. 2. Naked and dressed thermal manikin

Another part of our research was focused on firefighter movements. The number of existing ergonomics methods for assessing body postures is many and they vary in the area of the body they assess (Roman-Liu, 2014; Vujica Herzog, N. \& Buchmeister, B., 2015). Some methods assess the load on selected body part independently of each other and other methods provide a total assessment. Some methods focus on different work tasks such as repetitive and non-repetitive tasks and there are methods that evaluate static load e.g. load sustaining the same posture for a long time. Manual handling is another type of tasks that should be especially consider. For studying suitability of firefighter's movements, we selected two ergonomics methods: OWAS and RULA that can be performed manually or using software package. To shorten evaluation time, the examined workplace was designed and analyzed using Jack software package created by Technomatics. 


\section{Methodology}

For the presented problem consideration, the following steps were taken:

- Researching characteristics of protective clothes; through measuring heat transfer and thermal insulation. Three sets of measures were performed on different firefighter clothes and results were captured through user interface.

- Workplace analysis and evaluation; analysis of the existent environment with respect to working postures and workers' perceptions. The observation was conducted in Educational centre for protection and rescue Ig near Ljubljana during firefighter training (PKP project, 2014, funded by Slovene human resources development and scholarship fund).

- The extended OWAS method and RULA were used to evaluate the strains caused by different firefighter' postures during intervention.

- The examined workplace was designed and analysed using Jack software package created by Technomatics.

- Based on the results of OWAS and RULA analysis certain conclusions were made and suggestions for improving working conditions and preventing possible health problems in the future.

\subsection{OWAS method}

The OWAS method (Ovaco Working Analysing System) is a method of posture monitoring (Karhu et al., 1981; Vujica Herzog et al., 2014). This method originated from Finland's steel industry where body the positions of workers were analyzed using an elaboration observation method called OWAS. This method was initially successful and was therefore further developed and modified. It is considered to be a practical method for identifying and evaluating working postures. The OWAS procedure consists of two parts: an observational technique for classifying body postures, and a set of criteria for the redesigning of working methods and workplaces. Body postures are classified into 28 positions including the positions of the back (four positions), upper limbs (four), hands (three), lower limbs (nine), head and neck (five), as well as the load or force handled (three).

Each of these positions has pre-defined high risk and low risk postures that are coded by the observer. After calculating the amount of time the worker maintains these postures, the final step is to assign a four-level action code for task improvement. These four action codes are defined as follows: changes are not needed, changes needed in near future, changes needed immediately, need intensive observation.

\subsection{RULA}

The Rapid Upper Limb Assessment (RULA) was developed by Dr. Lynn McAtamney and Dr. Nigel Corlett (1993). This method evaluates individuals' exposures to postures, forces and muscle activities that that have been shown to contribute to Repetitive Strain Injuries. Use of this ergonomic evaluation approach results in a risk score between one and seven, where higher scores signify greater levels 
of apparent risk. A low RULA score does not guarantee that the workplace is free of ergonomic hazards, and a high score does not assure that a severe problem exists.

\subsection{Computer-Aided ergonomics analysis}

In order to assess the presented workplace the ergonomic software package Jack was used, as created by Siemens PLM. Jack is a complete system for generating 3D environments and interacting with them within a powerful graphical environment. It is based on a detailed link segment model with biologically accurate motion prediction and joint kinematics. When using Jack we can design real-time environment with interactive viewing, multiple windows, lights and cameras, textures, and mirrors.

\section{Results and discussion}

For researching characteristics of protective clothes heat transfer and thermal insulation was measured through user interface for data capturing (Fig. 3). The user interface is designed to ensure a good overview of all crucial data, temperature and power (Pahole et al., 2015). It enables simple and controlled testing according to ISO 15831 (2004) standard. Each of the nineteen segments communicates with the control unit and the data on the user interface is shown in real time.

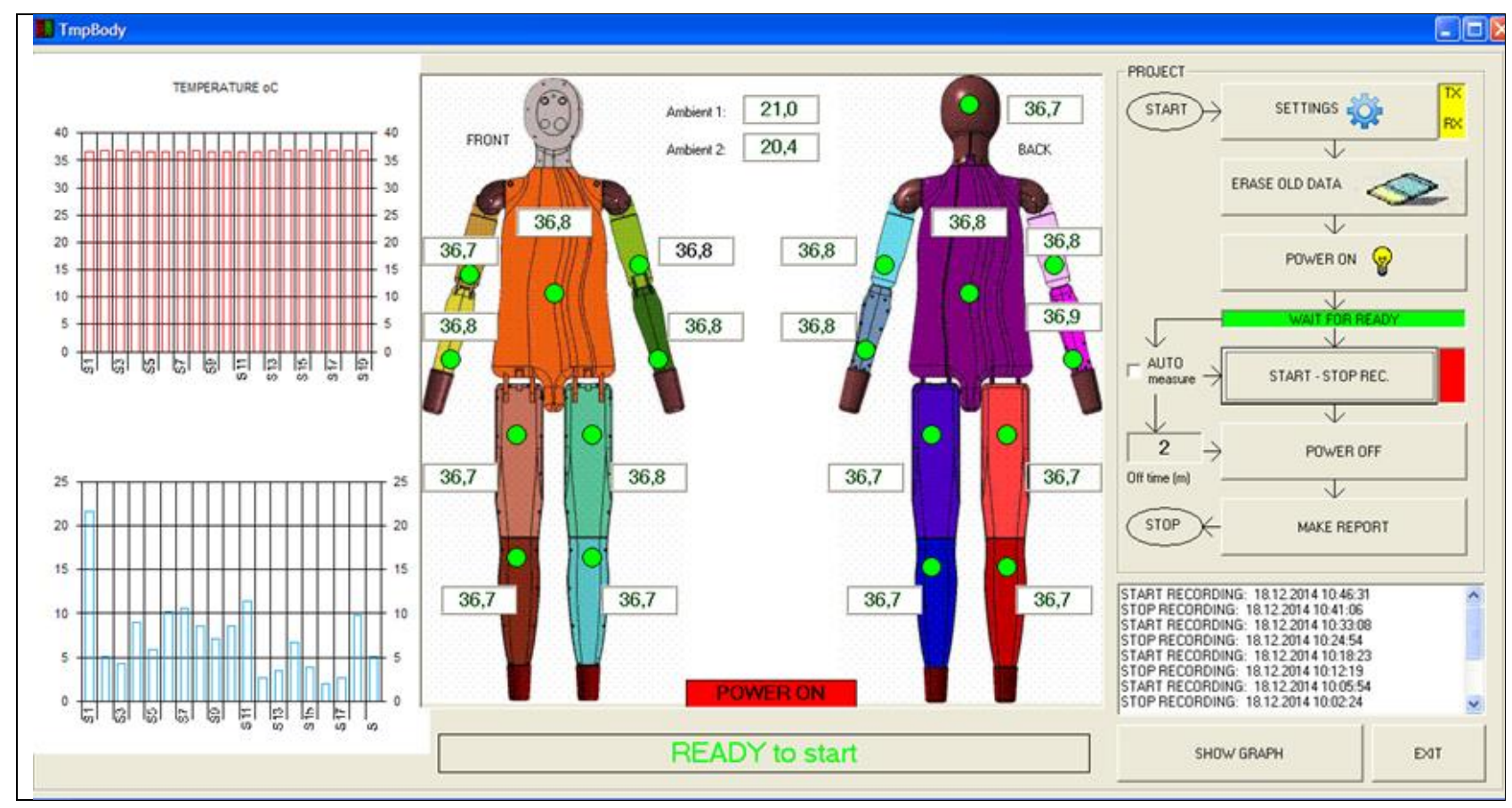

Fig. 3. TmpTelo interface (control panel)

In Figure 4 an example of measurement report is present for all nineteen measuring points and values for thermal insulation are presented also as graph on Figure 5.

Results show that thermal insulation changes regarding the number of clothes layers. Therefore it is very important to test also layers that firefighter wear under personal protective clothes. Each layer increase thermal insulation. 
Herzog, N. V. \& Buchmeister, B.: The Influence of Protective Equipment on Huma...

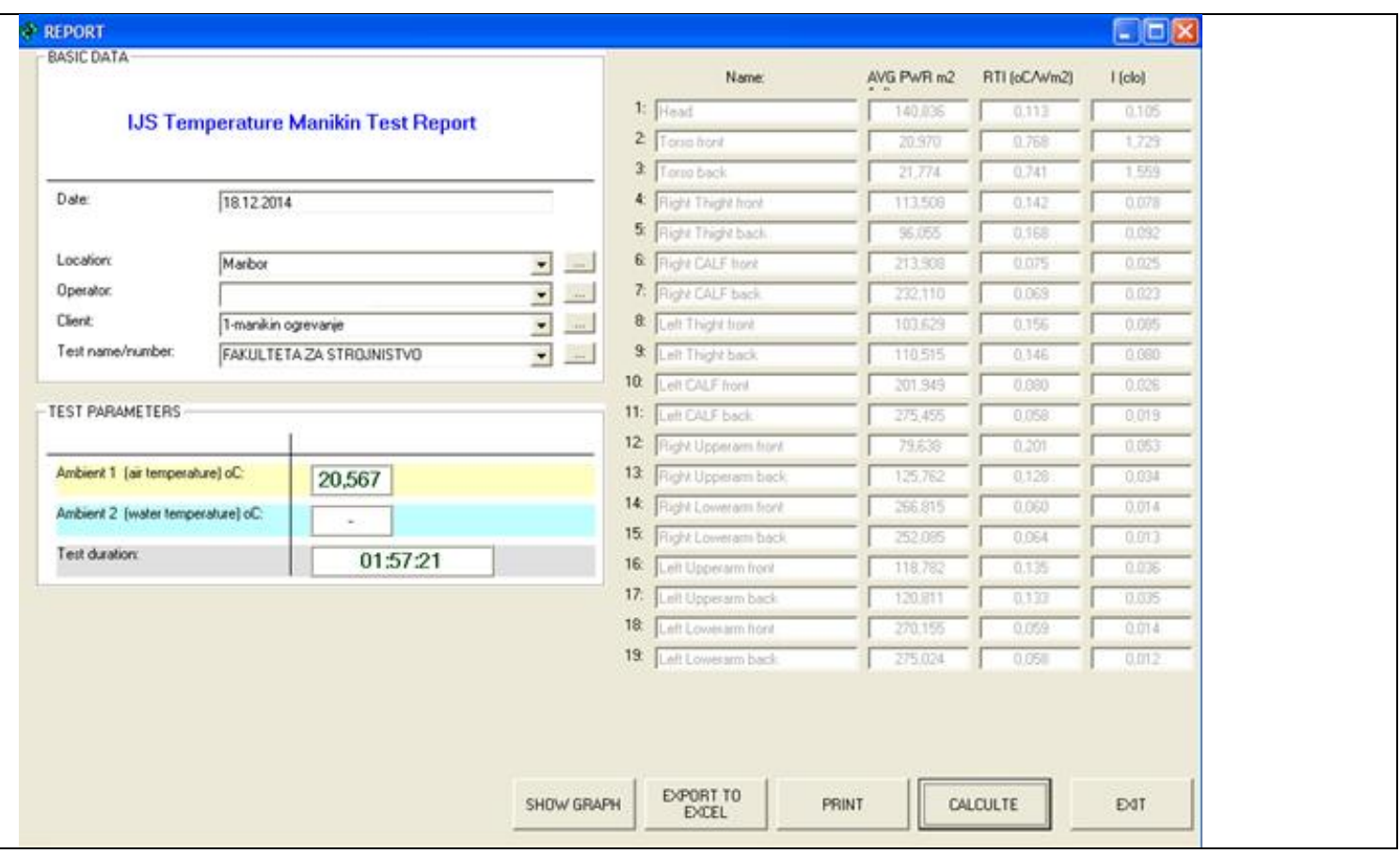

Fig. 4. An example of report

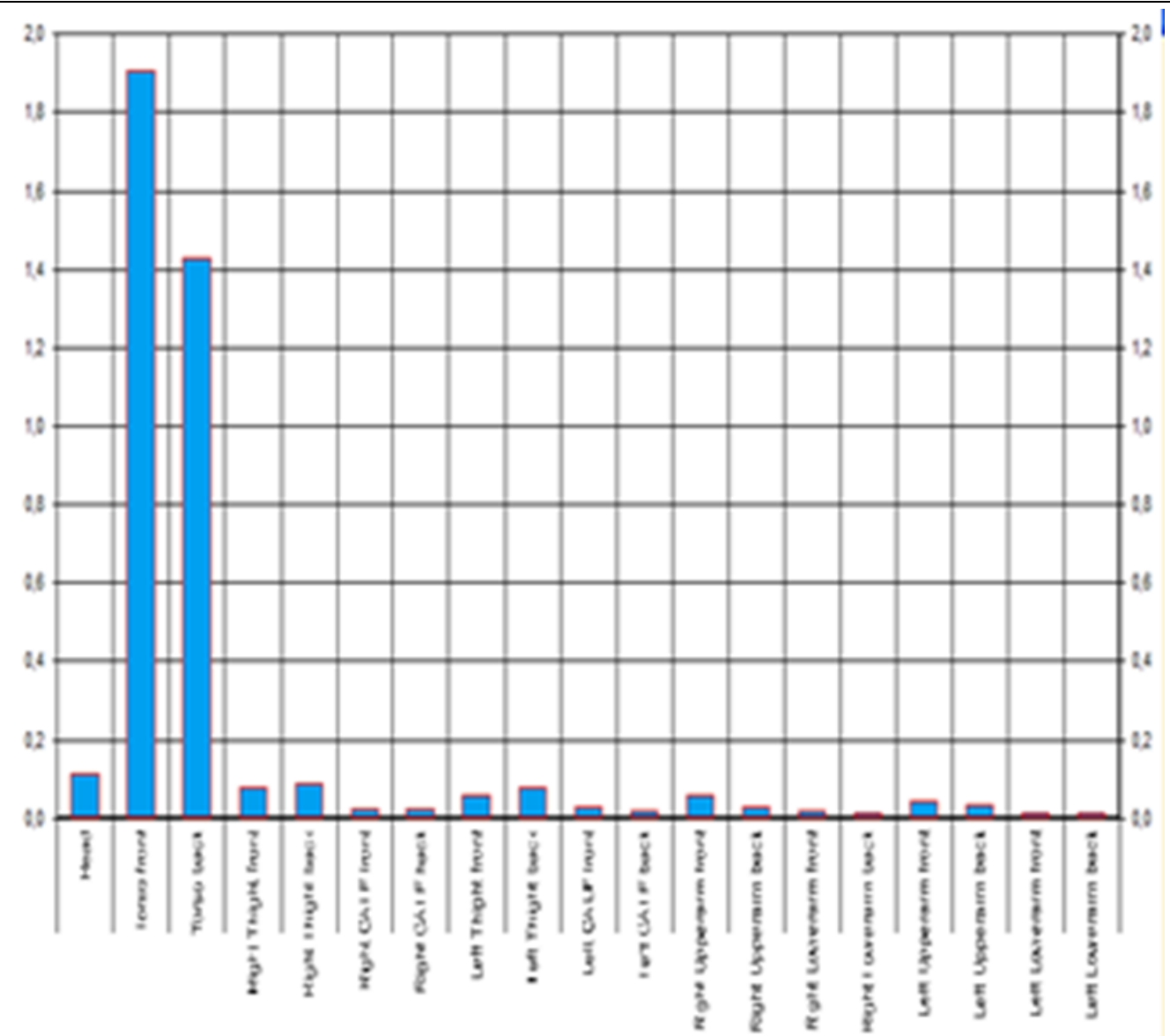

Fig. 5: Thermal insulation in all nineteen segments of thermal manikin

The highest values of thermal insulation were measured in segments 'torso front' and 'torso back' (Table 1) with values 3,75 and 3,179 Clo in room withought wind and 
with the temperature $21^{\circ} \mathrm{C}$. The lowest insulation was measured in part of left lower arm back with value 0,004 Clo.

\begin{tabular}{|c|l|c|}
\hline \multicolumn{2}{|l|}{ Insulation } & $\mathbf{1 - 3}$ \\
\hline 1 & Head & 0,053 \\
\hline 2 & Torso front & 3,75 \\
\hline 3 & Torso back & 3,179 \\
\hline 4 & Right Thigh front & 0,042 \\
\hline 5 & Right Thigh back & 0,049 \\
\hline 6 & Right Calf back & 0,008 \\
\hline 7 & Right Calf back & 0,008 \\
\hline 8 & Left Thigh front & 0,049 \\
\hline 9 & Left Thigh back & 0,039 \\
\hline 10 & Left Calf back & 0,009 \\
\hline 11 & Left Calf back & 0,007 \\
\hline 12 & Right Upper arm front & 0,025 \\
\hline 13 & Right Upper arm back & 0,018 \\
\hline 14 & Right Lower arm back & 0,005 \\
\hline 15 & Right Lower arm back & 0,004 \\
\hline 16 & Left Upper arm front & 0,018 \\
\hline 17 & Left Upper arm back & 0,018 \\
\hline 18 & Left Lower arm back & 0,005 \\
\hline 19 & Left Lower arm back & 0,004 \\
\hline
\end{tabular}

Tab. 1. Thermal insulation results (Third sample).

Second part of our research deals with firefighter movements. Analysis of existent environment with respect to working postures and workers' perceptions was made using OWAS and RULA ergonomic methods.

The observation was conducted in Educational centre for protection and rescue Ig (Figure 6) near Ljubljana during firefighter training (PKP project, 2014, funded by Slovene human resources development and scholarship fund). Since we decided for computer performed analyses we made video tapes during our visit in Ig to get reliable and valuable material for further work and research.

An example of simulation for firefighter work during intervention is shown in Figure 7 with detailed results of OWAS analyses on the right. We split the extinguishing process to three working phases: walking, squat on one knee and movements during extinguishing.

Regarding to OWAS analysis first phase 'walking' was signed with green colour meaning that work posture is normal and natural and there is no need for corrective measures. Results for second phase 'squat on one knee' were in orange colour that means that changes are needed immediately and the message appears that corrective measures must be taken as soon as possible. Also results for third phase 'movements during extinguishing' show very high loadings with the message that corrective actions are needed immediately. 
Herzog, N. V. \& Buchmeister, B.: The Influence of Protective Equipment on Huma...

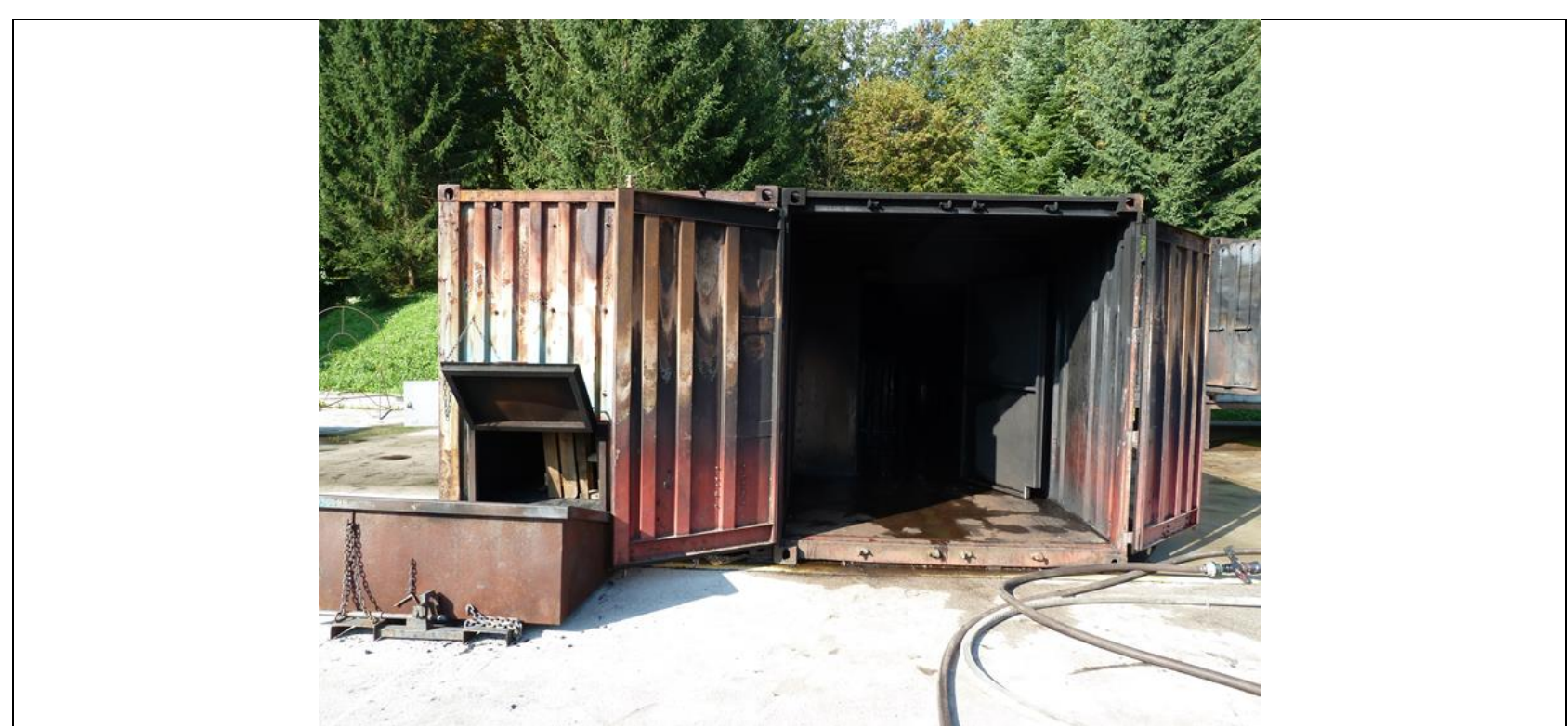

Fig. 6. Testing environment for firefighter training in Ig (PKP project)
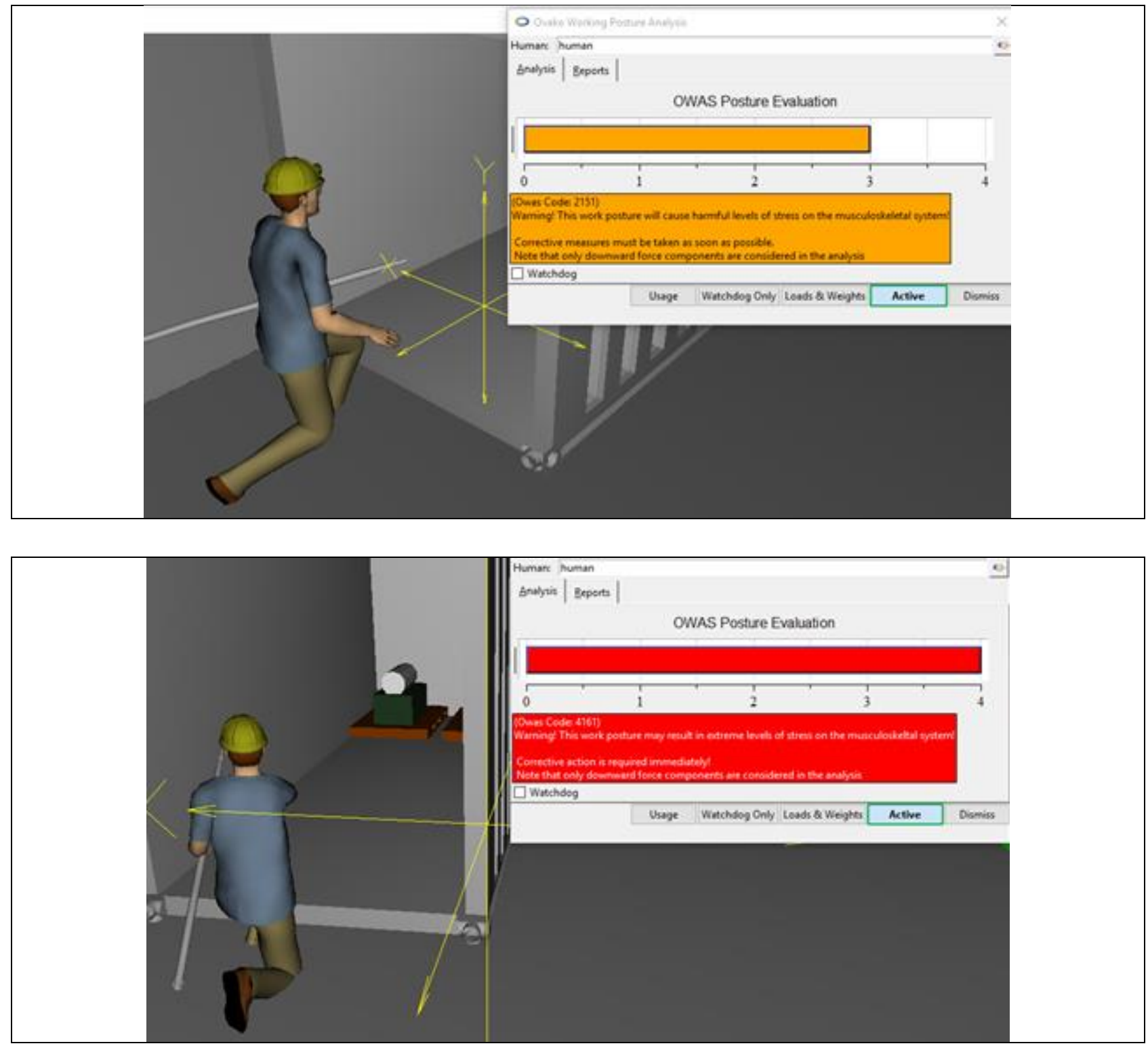

Fig. 7. Results of OWAS analysis during squat and usual movement by extinguishing 
Using Jack programme package RULA method was performed, too. Results analysis made by RULA method (figure 8) also show that further investigation is needed and that changes may be required.

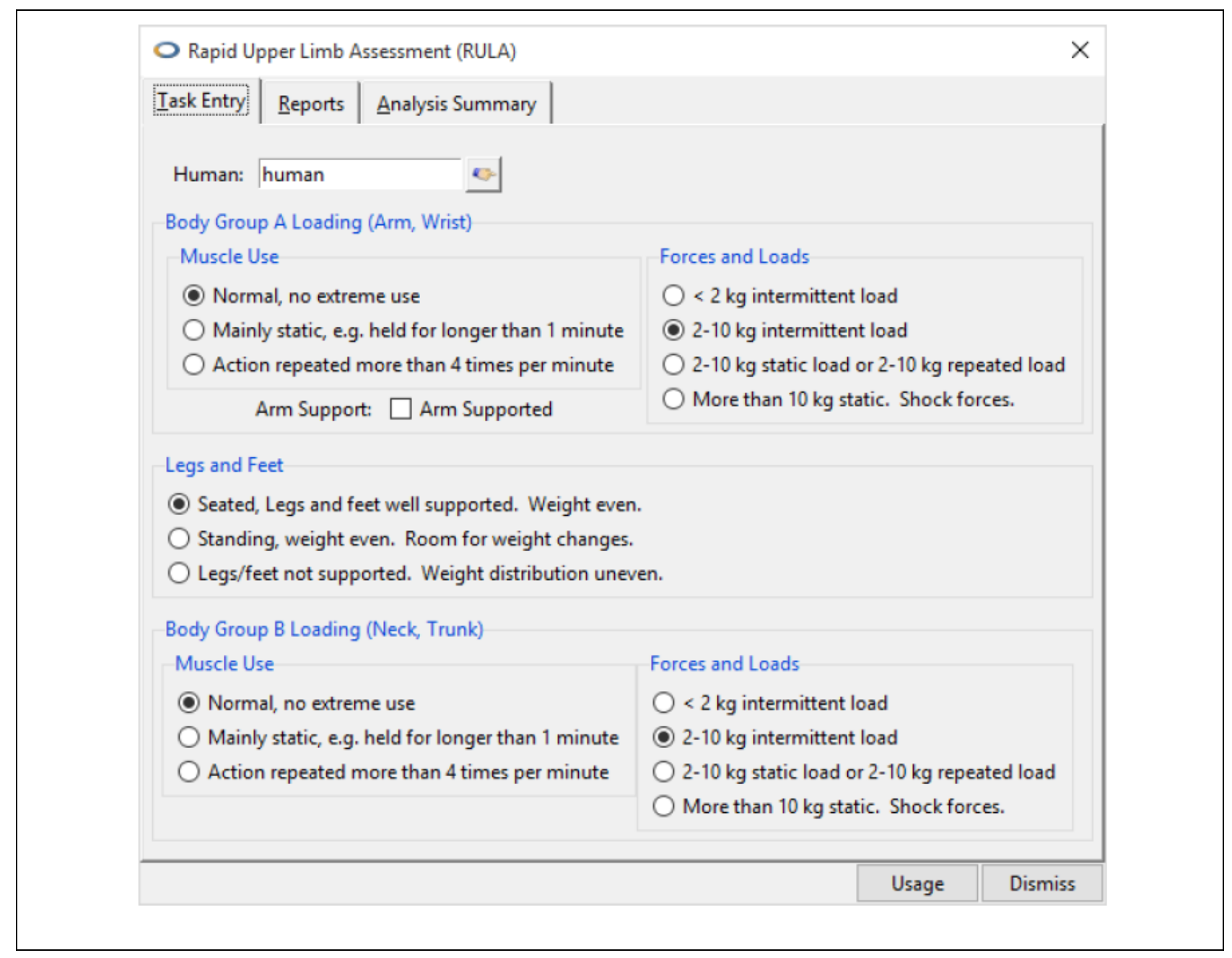

Fig. 8. Results of RULA analysis

\section{Conclusions}

It is generally known that working in bad and stressful environment may have long-term negative consequences on human health. During interventions, firefighters are exposed to strain and stress and above all they work in extreme thermal conditions.

To adjust firefighter conditions during work suitable clothes that will offer normal movement and comfort during work are very important. Within our research we tested different protective clothes and studied firefighter's movements during intervention.

Results of our research show that thermal insulation changes regarding the number of clothes layers. Each layer increase thermal insulation. In our research the highest value of thermal insulation was measured in segments 'torso front' and 'torso back' and the lowest insulation was measured in part of left lower arm back.

Regarding results of OWAS and RULA method can be concluded that movements that firefighter perform during intervention may be very harmful for his body and therefore high attention during intervention is of great importance. 
Herzog, N. V. \& Buchmeister, B.: The Influence of Protective Equipment on Huma...

\section{Acknowledgements}

Authors of this paper would like to thank Uroš Mušič for performed measurement made on thermal manikin and presented in his master thesis. We would also like to thank Slovene human resources development and scholarship fund that funded PKP project, 2014/15.

\section{References}

Andrejiova, M.; Kralikova, R.; Wessely, E.; Sokolova, H. (2012). Assesment of the Microclimate in the Work Environment, Chapter 42 in DAAAM International Scientific Book 2012, pp. 509-516, B. Katalinic (Ed.), Published by DAAAM International, ISBN 978-3-901509-86-5, ISSN 1726-9687, Vienna, Austria Holmér, I. (2004). Thermal manikin history and applications. European Journal of Applied Physiology, Vol. 92, No. 6, 614-618, ISSN: 1439-6319

ISO 15831 (2004) Clothing - physiological effects, Measurement of thermal insulation by means of a thermal manikin, International Organization for Standardization, Geneva, Switzerland

Karhu, O.; Harkoen, R.; Sorvali, P.; Vespalainen, P. (1981). Observing working postures in industry: examples of OWAS application. Applied Ergonomics, Vol. 12, No. 1, pp. 13-17, ISSN: 0003-6870

McAtamney, L.; Corlett, N. (1993). RULA: a survey method for the investigation of work-related upper limb disorders. Applied Ergonomics, Vol. 24, No. 2, pp. 91-99, ISSN: 0003-6870

Pahole, I.; Valentan, B.; Zavec Pavlinič, D.; Ficko, M.; Balič, J. (2015). Initial study of immersion thermal manikin development and its manufacture from solid blocks, Tehnički vjesnik, Vol. 22, No. 6, 1623-1631

Pavlinic, D. Z.; Wissler, E. H.; Mekjavic, I. B. (2011), Using a mathematical model of human temperature regulation to evaluate the impact of protective clothing on wearer thermal balance, Textile research journal, Vol. 81, No. 20, 2149 - 2159. Doi: $10.1177 / 0040517511414971$

Roman-Liu, D. (2014). Comparison of concepts in easy-to-use methods for MSD risk. Applied Ergonomics, Vol. 45, pp. 420-427, ISSN: 0003-6870

Vujica Herzog, N. \& Buchmeister, B. (2015). The review of ergonomics analysis for body postures assessment, Chapter 14 in DAAAM International Scientific Book 2015, pp. 153-164, B. Katalinic (Ed.), Published by DAAAM International, ISBN 978-390150998-8, ISSN 1726-9687, Vienna, Austria DOI: 10.2507/daaam.scibook.2015.14 Zavec Pavlinič, D.; Balič, J.; Ficko, M.; Katalinič, B. (editor), (2014). Functional products development: advanced tools and concepts, (DAAAM publishing series Manufacturing technology). Vienna: DAAAM International, II, ISBN 978-3-90150995-7

Vujica Herzog, N.; Vujica Beharic, R.; Beharic, A.; Buchmeister, B. (2014). Ergonomic analysis of ophthalmic nurse workplace using 3D simulation, International Journal of Simmulation Modelling, Vol. 13, No. 4, 409-418, ISSN 1726-4529 